\title{
Music and Anthropogenic Climate Change: An Evolutionary Perspective ${ }^{1}$
}

\section{Federico Andreoni, McGill University}

\begin{abstract}
Anthropogenic climate change (i.e., climate change generated by human activities) requires solutions that are grounded in both thoughtful analysis and emotional responses, promoting the creation of social bonding and the development of a common desire to implement changes in our personal lives and society at large. In this article, I use a biopsychosocial approach - an approach that takes into account biological, psychological, and socio-environmental factors - to study the role of music in eliciting emotions and enhancing social bonding. This approach will allow me to contextualize the role of music within the findings of current evolutionary theories of music, that is music theories that study the evolutionary function of music and show that music's ability to unite people in the fight against climate change stems from its evolutionary role as a survival mechanism.
\end{abstract}

Keywords: climate change, evolutionary theories, music, social bonding.

$\mathrm{M}$ usic composed to raise awareness about anthropogenic climate change, that is human-caused climate change, is not limited to a specific music genre; in fact, music of all types and forms has been used to raise such awareness - from jazz to religious music, rap, and opera. In 2019, the band COPUS performed a new jazz and spoken-word composition entitled "What if we...?" during the GFDRR and World Bank Group's The Art of Resilience programme. The programme brought together a cast of artists and scientists from across the world to demonstrate how art can play an influential role alongside science to support disaster relief efforts and help diminish the impact of climate change. ${ }^{2}$ The opera $\mathrm{CO}_{2}$, with music by Giorgio Battistelli and libretto by Ian Burton, first staged at La Scala, Milan, in 2015, is yet another example of how music for climate change has been inclusive in its selection of music genres and traditions from across the globe. $\mathrm{CO}_{2}$ is an opera that portrays the effects of greenhouse gases on the earth's atmosphere, and specifically "deals with the difficult relationship, maybe of love, of drama, of jealousy, of abuse, between mankind and nature, between humankind and its own environment."3

The core message of these artistic projects, like that of many other music-related initiatives meant to raise awareness about climate change, has spread widely, predominantly thanks to the development of digital platforms, which allow artists to convey social messages across the globe quickly and efficiently. In the past two decades, the increasing adoption of digital platforms has created a thriving network of new cultural and research initiatives that include, among others, discussions about the relationship between cli-

1. As a study centered on human activities (e.g., music making) and behavior (e.g., social gatherings), this article focuses exclusively on issues related to anthropogenic climate change. Effects of these changes on non-human life forms are beyond the scope and focus of this paper. Moreover, in this paper I use the term climate change to indicate anthropogenic climate change. I would like to thank Afra Saskia Tucker for her help with the editing of this paper.

2. "About the Art of Resilience," The Art of Resilience, accessed March 25, 2020, https://www.artofresilience.art/about/. The Art of Resilience is an ongoing program organized by the Labs team of the Global Facility for Disaster Reduction and Recovery (GFDRR) and the World Bank Group.

3. "Intoxicating Climate Change Opera 'CO2' at La Scala Milan," Euronews, May 20, 2015, https://www.euronews.com /2015/05/20/intoxicating-climate-change-opera-co2-at-la-scala-milan. 